\title{
Anti-metastatic action of anacardic acid targets VEGF-induced signalling pathways in epithelial to mesenchymal transition
}

\author{
Puttananjaiah Shilpa ${ }^{1, *}$, Keshavaiah Kaveri ${ }^{1,2, *}$, Bharathi P Salimath ${ }^{1,3, * *}$ \\ ${ }^{1}$ Department of Studies in Biotechnology, University of Mysore, Manasagangotri, Mysore, India; \\ ${ }^{2}$ Maharani's PU College, Narayanasastri road, Mysore, India; \\ ${ }^{3}$ Petit Institute for Bioengineering and Bioscience, Georgia Institute of Technology, Atlanta, GA, USA.
}

\begin{abstract}
Summary Anacardic acid is a major constituent of nutshell of cashew. In this study, we have isolated it from the leaves of Anacardium Occidentale L. using polarity-based fractionation and confirmed the structure using GC-MS, NMR and FT-IR. The main focus of this study is to harness the molecular mechanism of anti-metastatic action of anacardic acid (A1). We have used MCF-7, a weak metastatic and U-87, a highly metastatic, breast and glioma cell lines respectively, for our study. We have shown that VEGF increases migration and invasion activities of MCF-7 cells, upon overexpression of Twist and Snail genes. It is observed from the current study that exposure of MCF-7 cells to A1 resulted in upregulation of epithelial marker E-cadherin with a concomitant decrease in the expression of mesenchymal markers Twist and Snail gene expression besides exhibiting a strong anti-migratory and anti-invasive activity. In metastatic U-87 glioma cells, treatment with A1 decreased the phosphorylation of MAP kinases, inhibited the translocation of Sp1 and down regulated VEGF and Flt-1 gene expression. Overall, the current findings demonstrate for the first time that anacardic acid functions as a potent EMT inhibitor by targeting VEGF signaling pathway, providing a novel template for drug discovery.
\end{abstract}

Keywords: Anacardium occidentale L., anacardic acid, epithelial to mesenchymal transition, antimetastatic, vascular endothelial growth factor

\section{Introduction}

Anacardium occidentale L., a member belonging to Anacardiaceae family, has a great economic and medicinal value (1). A. occidentale $\mathrm{L}$. has been found to have antibacterial, antiulcer, antitumor activity through suppression of hypoxia and angiogenic factors (2). Anacardium nut oil has been shown to have an apoptotic effect on tumor cell lines like acute myeloblastic leukemia, breast carcinoma, and cervical epithelial carcinoma (3). Sheela et al. has shown that an ethanolic extract of $A$. occidentale L. leaves suppresses vascular endothelial growth factor (VEGF) induced angiogenesis of both in vivo and in vitro (4). Nevertheless, studies either directly comparing non angiogenic role of VEGF

\footnotetext{
*These authors contributed equally to this works.

**Address correspondence to:

Dr. Bharathi P Salimath, Department of Biotechnology, University of Mysore, Manasagangotri, Mysore 560006, India.

E-mail: salimathuom@gmail.com
}

to $A$. occidentale L. or its antimetastatic activity has not been well studied. In the present paper, an attempt to understand the anti-metastatic efficacy of anacardic acid (A1) in tumeriogenic but weakly metastatic breast cancer cells (MCF-7) and highly metastatic brain tumor cells, glioblastoma multiforme (U-87) is made.

Greater than $90 \%$ of deaths in breast cancer are attributed to metastatic disease where the primary tumor has invaded distant sites. To infiltrate host tissues, carcinoma cells of primary tumor separate from the tumor mass by breaking their basement membrane and cell-cell contacts, known as adherens junctions (57). Functional loss of E-cadherin has been reported to induce epithelial-mesenchymal transition (EMT) in several cancers $(8,9)$. The resulting cells lose their flexible structure and enhance migration through the extracellular matrix $(10,11)$. Until now, many growth factors including HGF, TGF- $\beta$, and EGF have been found to induce EMT (12). Recent research suggests that VEGF signalling is not limited to angiogenesis, but plays an important role in breast cancer cell migration 
and invasion (13). Most of the growth factors which induce EMT activation and modulation of transcription factors repress epithelial genes, such as those encoding E-cadherin and cytokeratins, and activate transcription programmes which specify fibroblast-like motility and an invasive phenotype $(14,15)$. Transcription factors like Twist, Snail basic Helix Loop Helix (bHLH) families, two double zinc finger and homeodomain (ZEB) factors trigger EMT (16). Previously it has been shown that Twist and Snail transcription factors play key role during EMT by repressing the E-cadherin, the major epithelial cell adhesion molecule. However, it has recently been shown that over-expression of Twist in breast cancer animal model regulates EMT by promoting tumor cell invasion. The ectopic expression of Twist resulted in EMT and induced metastasis in cells.

Many studies have revealed that natural compounds act as antiangiogenic and apoptotic agents against human cancers. However, there is a continued search for novel nontoxic components for treating metastatic tumors. In the present study, an effort has been made to elucidate the molecular mechanisms involved in the anti-angiogenic and anti-metastatic effect of the compound A1 against breast cancer (MCF-7 cells) and highly metastatic glioma, (U-87 cells). Moreover, in the present study, MCF-7 cells are stimulated with VEGF, to demonstrate that $\mathrm{MCF}-7$ cells exhibit epithelial phenotype with high expression of E-cadherin and less expression of detectable mesenchymal markers. It is also shown from the current studies that A1 inhibits proliferation, migration and invasion of MCF-7 breast cancer cells. In addition, it is also shown from the current research that the interplay of A1 with EMT regulators such as E-cadherin, Twist and Snail in order to inhibit metastasis of MCF-7 cells. Further the cellular and molecular mechanisms underlying the regulation of EMT by VEGF, Twist, and Snail and signaling pathway governing the same have been elucidated.

\section{Materials and Methods}

\subsection{Cell culture}

MCF-7 (non-metastatic breast cancer cell line), U-87 (most aggressive malignant primary brain cancer cell line) and HEK293 cells (Normal human embryonic kidney cells) are obtained from National Centre for Cell Science (NCCS); Pune, INDIA. Cells are cultured in Dulbecco's modified Eagle's medium (DMEM; Gibco, USA). Culture medium is supplemented with $10 \%$ Fetal Bovine Serum (FBS) and 100 units $/ \mathrm{ml}$ Streptomycin and Penicillin from GIBCO laboratories, Grand Island, NY, USA). [ $\left.{ }^{3} \mathrm{H}\right]$ thymidine is procured from the Baba Atomic Research Centre, Mumbai, India. Mammalian transfection assay kits, luciferase, CAT and $\beta$-galactosidase assay kits are from Promega, USA. All other reagents used are of the highest analytical grade.

\subsection{Processing of A. occidentale leaves and purification} of the active compound

The shade-dried leaves $(1 \mathrm{~kg})$ are powdered and extracted using $5 \mathrm{~L}$ of methanol at room temperature for $24 \mathrm{~h}$. Polarity-based partial fractionation of the methanol extract is carried out using solvents such as hexane, ethyl acetate, and triple distilled water. The solvents are evaporated by rotary evaporator and all the fractions are verified for anti-angiogenic activity using human umbilical vein endothelial cells (HUVECs) tube formation assay. The ethyl acetate extract which exhibited positive activity, is further subjected to silica gel column chromatography (Merck 60-200 mesh size) and eluted with differential ratios of ethyl acetate: methanol (100:0, 95:5, 90:10, 50:50, and 0:100). The sub-fractions collected are subjected to TLC using ethyl acetate: methanol as a solvent system. The fraction EA 1 (ethyl acetate: methanol (100:0) that showed the maximum inhibitory effect on tube formation by HUVEC's is further subjected for purification (silica gel column chromatography, Merck 60-200 mesh size) and eluted with ethyl acetate: methanol (50:50 to 0:100) to obtain seven sub fractions (EA 1.1 to EA 1.7); with EA 1.1 being the most active component. EA 1.1 is further subjected to column chromatography using neutral alumina (Grade 3 ) to remove unwanted pigments (Scheme 1). The active compound thus obtained is validated and structurally characterized.

\subsection{High-performance liquid chromatography (HPLC) and spectral studies}

HPLC purification is carried out using a modular HPLC instrument (Ultrasep ES 10 RP $186.0 \mu \mathrm{m}$, reverse phase C18 column) (Tokyo, Japan). The mobile phase is chloroform/ethyl acetate $(80: 20)$ at $1.80 \mathrm{~mL} / \mathrm{min}$; absorbance is monitored at $280 \mathrm{~nm}$. Each analysis is carried out by dissolving $25 \mathrm{mg}$ of sample in $5 \mathrm{~mL}$ of ethyl acetate. The flow rate of the sample is $1 \mathrm{~mL} / \mathrm{min}$ and ran for $30 \mathrm{~min}$.

GC-MS of the isolated compound is done in Thermo LCQ Deca XP MAX (Bremen, Germany) (Range: $m / z=$ $1-900)$. GC-MS recorded the retention time and mass to charge ratio $(\mathrm{m} / \mathrm{z})$. These experiments are carried out at Department of Chemistry, Indian Institute of Science, Bangalore, Karnataka, India.

${ }^{1} \mathrm{H}$ NMR spectrum is recorded on a Varian T-60 spectrometer and ${ }^{13} \mathrm{C}$ NMR spectrum is obtained on a Bruker WH-270 (Chicago, USA) machine at a probe temperature of $25^{\circ} \mathrm{C}$. Spectra $\left({ }^{1} \mathrm{H}\right.$ NMR, ${ }^{13} \mathrm{C}$ NMR) are recorded using $10 \mathrm{mg}$ of the sample dissolved in $1 \mathrm{~mL}$ of chloroform and chemical shifts are reported relative to tetramethylsilane (TMS) in ppm and coupling constants in hertz. These experiments are performed at NMR research centre, Indian Institute of Science, Bangalore, Karnataka, India. All solvents used are 

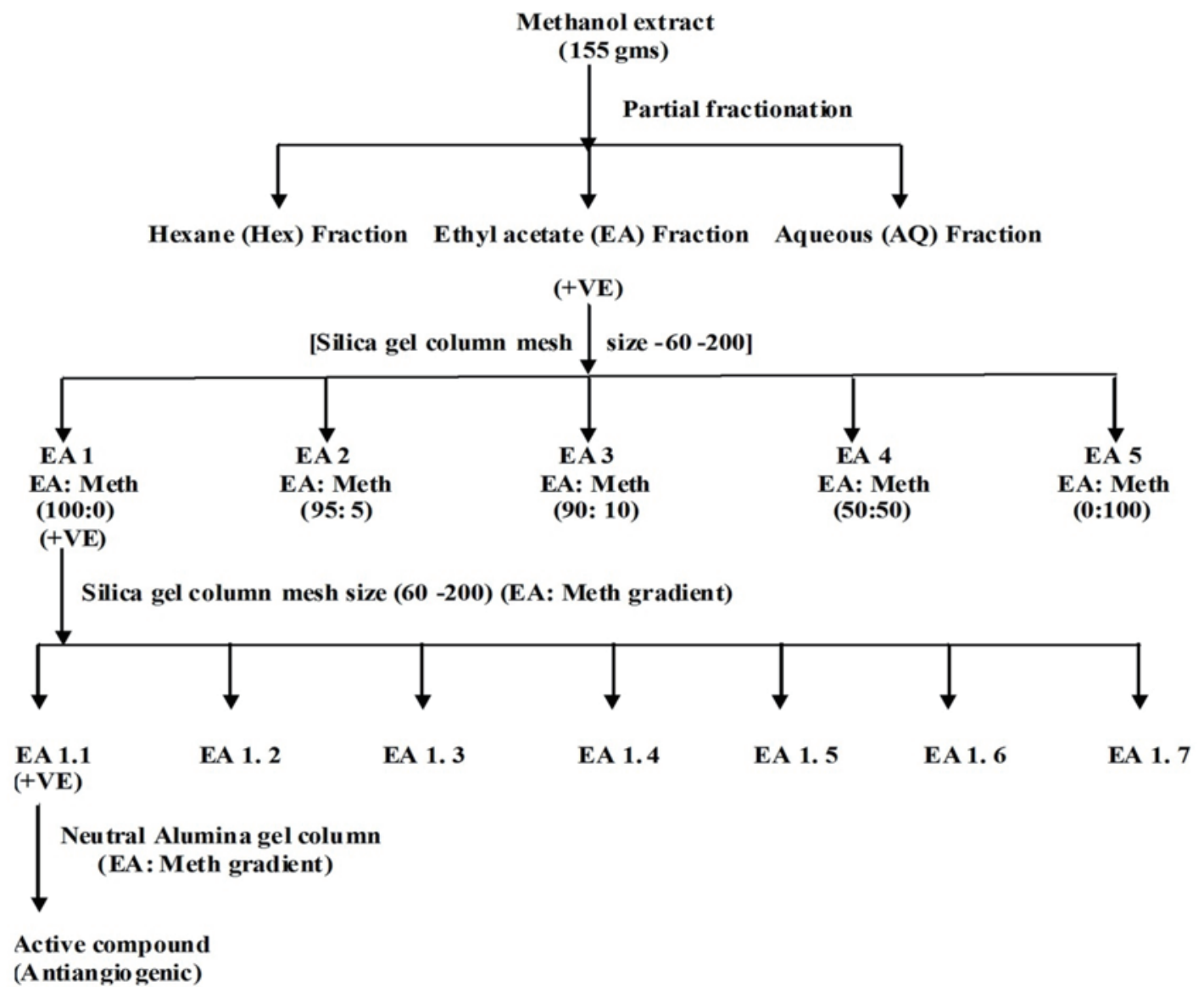

Scheme 1. General scheme followed for the extraction and purification of active substance from $A$. occidentale.

distilled prior to use.

The UV-visible absorption spectrum of the active compound is measured using a Hitachi U3400 spectrophotometer (El Cajon, CA, USA). The compound is dissolved in chloroform to a final concentration of approximately $1 \mathrm{mg} / \mathrm{mL}$ and then filtered. The filtrate is used for recording the spectrum. The spectrum is recorded for two different portions for consistency.

The FT-IR spectrum of the active compound is recorded using Bruker FT-IR Multiscan 15 Sf II (Ettlingen, Germany) instrument employing the $\mathrm{KBr}$ pellet technique. Approximately $0.2 \mathrm{mg}$ of isolated compound is thoroughly mixed with $300 \mathrm{mg}$ of $\mathrm{KBr}$ to prepare the sample pellet.

\subsection{Endothelial cell tube formation assay}

Tube formation of HUVECs is performed as per manufacturer's instructions (17). Briefly, a 96 well plate is coated with $50 \mu \mathrm{L}$ of matrigel which is allowed to solidify at $37^{\circ} \mathrm{C}$ for $1 \mathrm{~h}$. HUVECs $\left(4 \times 10^{4}\right.$ cells/ well) are seeded on the solidified matrigel and cultured in EGM containing various concentrations of active compound A1 $(0.01 \mathrm{~g}, 0.1 \mu \mathrm{g}, 0.5 \mu \mathrm{g}, 1 \mu \mathrm{g}$ and $2 \mu \mathrm{g})$ for $24 \mathrm{~h}$. VEGF $(10 \mathrm{ng})$ is added to induce tube formation to each well except for the control without VEGF. After incubation at $37^{\circ} \mathrm{C}$ and $5 \% \mathrm{CO}_{2}$ the enclosed networks of complete tubes from five randomly chosen fields are photographed using an inverted microscope with an attached CCD camera (Carl Zeiss, Germany).

\subsection{Transient transfection and ectopic expression of genes}

To determine the effect of VEGF and/ or A1 on proliferation, migration and invasion activities of MCF7 cells, cells are seeded in six well plates and cultured to $60-70 \%$ confluency prior to transient transfection. On the subsequent day, cells (MCF-7) are transfected with pGL3 plasmid containing human gene construct of E-cad -624bp or Twist -824 bp or Snail -900 bp using calcium phosphate transfection kit (Promega, USA) as per the manufacturers instruction. A similar protocol is used to transfect U-87 or HEK293 cells. These cells are transfected with pLUC plasmid containing human gene construct of VEGF promoter site $(-2,068$ bp to $+50 \mathrm{bp})$ with a luciferase reporter gene. The transfected cells are used for the following assays.

\subsection{Cell proliferation assay}

In vitro cell proliferation assay is carried out using $\left[{ }^{3} \mathrm{H}\right]$ thymidine incorporation into DNA in rapidly multiplying cells as described earlier (18). The Twist 
or Snail gene transfected cells $\left(1 \times 10^{4}\right.$ cells/well $)$ are seeded on 12-well plates in DMEM media and grown in $5 \% \mathrm{CO}_{2}$ at $37^{\circ} \mathrm{C}$ for $48 \mathrm{~h}$. On the third day, $\left[{ }^{3} \mathrm{H}\right]$ thymidine $(1 \mu \mathrm{Ci} / \mathrm{mL}$ medium $)$ is added and the effect of VEGF $(10 \mathrm{ng})$ or A1 $(50 \mu \mathrm{M})$ is tested on proliferation of transfected cells. After $48 \mathrm{~h}$, the cells are trypsinized and washed with phosphate-buffered saline (PBS) and high molecular weight DNA is precipitated using ice-cold trichloroacetic acid (10\%). Scintillation fluid $(5 \mathrm{~mL})$ is added to all the samples and radioactivity is measured in a liquid scintillation counter (Perkin Elmer Tri-Carb 2900 TR, Downer's groove, IL, USA).

\subsection{Transwell invasion assay}

Invasion assay is performed as described earlier (19). Twist or Snail gene transfected or untransfected MCF-7 $\left(2 \times 10^{4}\right.$ cells per well) cells are treated with mitomycin $\mathrm{C}(10 \mathrm{ng} / \mathrm{mL})$ for $2 \mathrm{~h}$ and seeded onto the top chamber of transwell which is precoated with $0.1 \%$ gelatin. The bottom chamber of transwell is filled with basal media containing VEGF $(10 \mathrm{ng} / \mathrm{mL})$ or A1 $(50 \mu \mathrm{M})$ or VEGF and A1, followed by overnight incubation. The non-migrated cells are swabbed using cotton bud and gelatine coated transwells are fixed with $4 \%$ ice cold paraformaldehyde and cells are stained using haematoxylin. The cells are photographed under an inverted microscope. The cells are measured using ImageJ (version1.47).

\subsection{Cell migration assay (scratch assay)}

MCF-7 cells $\left(1 \times 10^{5}\right)$ ectopically expressing either Twist or Snail gene inserts are cultured to a confluent monolayer. The assay is performed as described earlier (20). The cells are serum starved overnight prior to treatment with mitomycin-C (10 ng/mL) for $2 \mathrm{~h}$. The monolayer is wounded using $200 \mu \mathrm{L}$ pipette tip. Fresh basal media is added followed by treatment with or without VEGF $(10 \mathrm{ng})$ or A1 $(50 \mu \mathrm{M})$ and incubated at $37^{\circ} \mathrm{C}$ and $5 \% \mathrm{CO}_{2}$. The movement of cells in the scratched area are photographically monitored at 0 and $24 \mathrm{~h}$ after the treatment using an inverted microscope. The cells are measured using Image J (version1.47).

\subsection{Gene (VEGF/E-cadherin/Twist/Snail) promoter and luciferase reporter gene analysis}

In order to determine the effect of A1 on regulation of E-cadherin, Twist or Snail gene expression in MCF-7 cells and VEGF gene expression in U-87 and HEK293 cells; respective gene promoter-luciferase reporter assays are performed. Cells are transiently transfected as mentioned above. The transfected cells are incubated for different time intervals either with or without VEGF (10 ng) or A1 $(50 \mu \mathrm{M})$ or VEGF and A1. Cell extracts were prepared and assayed for luciferase activity using the luciferase assay kit.

\subsection{Flt-1 gene promoter CAT enzyme reporter assay}

U-87 and HEK293 cells are transiently transfected with $2 \mu \mathrm{g}$ of Flt-1 CAT reporter plasmid. After $24 \mathrm{~h}$ of transfection, the cells are serum starved overnight and treated with or without VEGF or A1 or VEGF+ A1 for $48 \mathrm{~h}$. pRSV- $\beta$ gal is co-transfected to serve as an internal control for transfection efficiency. After $48 \mathrm{~h}$ of transfection, cell extract are prepared and assayed for CAT activity using CAT assay kit (Promega, USA).

\subsection{Immunoblot analysis of JNK and ERK activity}

The activity of ERK or JNK is measured by western blotting. Briefly, U-87 cells are grown to confluency, and serum starved for $24 \mathrm{~h}$. Cells are incubated with or without VEGF $(10 \mathrm{ng} / \mathrm{mL})$ or A1 $(50 \mu \mathrm{M})$ for different time intervals $(0,2,5,10,15,30$, and $60 \mathrm{~min})$. Cells are washed with $\mathrm{PBS}$, collected in modified cold radio immune precipitation buffer (RIPA) and homogenized on ice. Extracts are clarified at $10,000 \mathrm{~g} / 30 \mathrm{~min} / 4^{\circ} \mathrm{C}$. The proteins were separated on SDS PAGE and transferred to a PVDF membrane. The membranes are incubated with antibodies against anti-pJNK and anti-pERK respectively. The membranes were then developed using the Luminol reagent and analyzed using phosphor image analyzer (Fujifilm, FLA5000, Tokyo, Japan).

\subsection{Electrophoretic mobility shift assay (EMSA)}

Extraction of nuclear proteins and electrophoretic mobility shift assay (EMSA) are performed. Briefly, U-87 cells are grown to $80-90 \%$ confluency in petri plates and are serum deprived for $12 \mathrm{~h}$ before treatment. Cells are then treated with $50 \mu \mathrm{M}$ of A1 with different time intervals $(4,8,16,32$, and 48 h). Nuclear extract prepared from U-87 is used to examine the effect of A1 on Sp1-DNA binding activity using specific oligonucleotide probe for Sp1 binding element in the VEGF gene.

\subsection{Statistical analyses}

Unless stated otherwise, all experiments were performed in triplicates. Wherever appropriate, the data are expressed as mean and compared using oneway analysis of variance. Statistical significance of differences between control, A1, VEGF, VEGF and A1 treated cells are determined by Duncan's multiple range test (DMRT). For all tests, $p<0.05$ is considered statistically significant. All of the analyses are performed using the SPSS for Windows, version 13.0 (SPSS Inc.). 


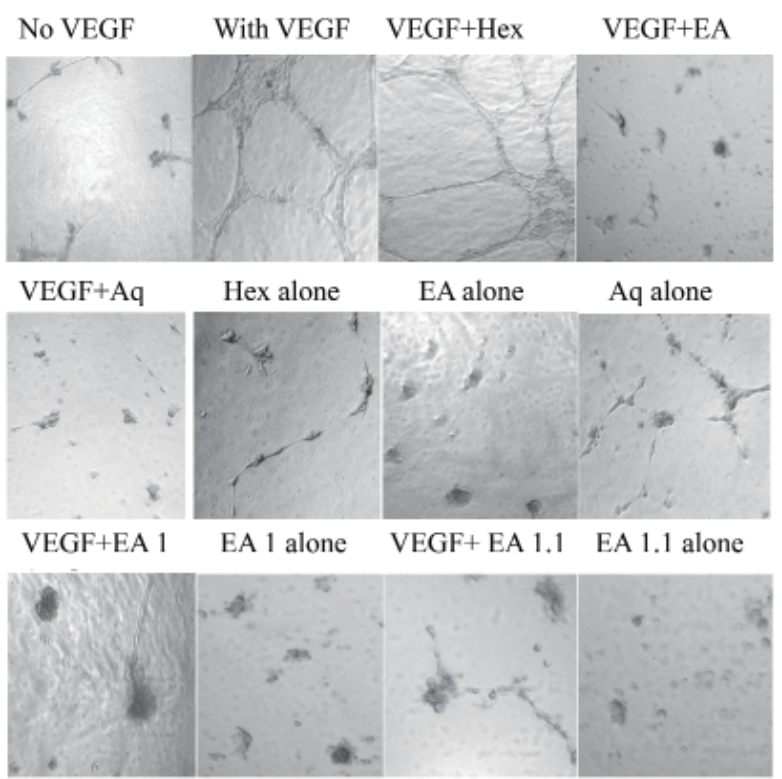

Figure 1. Effect of different fraction of $\boldsymbol{A}$. occidentale extract on VEGF- induced tube formation. HUVECs (1 $\times 10^{4}$ cells) cultured in EGM with $5 \mu \mathrm{g}$ of different fractions and sub-fractions were added to the matrigel coated 96 well plate. After incubation for 8 hours at $37^{\circ} \mathrm{C}$, capillary networks were photographed and quantified (Magnification: 40×). All data are presented as mean from different experiments with triplicates and means of $\pm \operatorname{SEM}(n=3)$.

\section{Results}

\subsection{Isolation and characterization of the anti-angiogenic compound from A. occidentale}

The effect of hexane, ethyl acetate and water extracted compounds on in vitro tube formation assay is shown in Figure 1. In, VEGF induced formation of tube like structures and the extracts per se did not have any effect on the growth of endothelial cell-tubes. However, ethyl acetate fraction (EA 1.1) showed positive antiangiogenic activity against HUVECs ability to form tube like structures; and ethyl acetate fraction is selected for further purification (Figure 1). The active fraction obtained after passing through alumina gel column, when subjected to TLC, showed a single band (Supplementary Figure 1a, http://www.ddtjournal.com/ docindex. php? year $=2015 \&$ kanno $=1$ ) which is scraped and used for further analysis.

\subsection{HPLC and GC-MS profile of the active compound}

In the HPLC analysis (Supplementary Figure $1 \mathrm{~b}$, http://www.ddtjournal.com/docindex. php? year $=2015 \&$ kanno $=1$ ), the extracted compound gave three peaks which are observed at retention times of $5.45,6.71$, and $9.12 \mathrm{~min}$ with a ratio of the integrated peak area of 3:1:2 respectively. Anacardic acid isolated from natural cashew nut shell liquid (CNSL) using supercritical carbon dioxide $\left(\mathrm{scCO}_{2}\right)$ has revealed a similar HPLC profile which showed three peaks observed at retention times of 5.47, 6.69 and 9.23 min with a ratio of the integrated peak area $3: 1: 2$ respectively $(21)$.

In GC-MS analysis (Supplementary Figure 2, http://www.ddtjournal.com/docindex. php? year $=2015$ \&kanno $=1$ ), the extracted compound showed three major peaks with molecular ions of $\mathrm{m} /$ $z($ mass $/$ charge $)=343.104,345.411$, and 347.231, matching the three peaks observed in HPLC analysis. These three HPLC peaks correspond to anacardic acid components with tri-, di- and monoene in their alkenyl side chains with abundances of $51 \%, 18 \%$, and $31 \%$ respectively. In addition, a relatively weak peak with a molecular ion of $\mathrm{m} / z=351.436$ is observed which corresponds to the anacardic acid component with a saturated side chain. Similar LC-MS analysis results are reported for $\mathrm{scCO}_{2}$ extracted anacardic acid which showed three major peaks with molecular ions of $\mathrm{m} / \mathrm{e}=$ $343.284,345.304$, and 347.327 respectively (22).

Fraction EA 1.1, extracted from the leaves of $A$. occidentale is eluted in mobile phase ethyl acetate/ methanol (9:1), detected by UV $254 \mathrm{~nm}$.

HPLC purification carried out using a modular HPLC instrument Ultrasep ES 10 RP $186.0 \mu \mathrm{m}$ reverse phase C18 column. Mobile phase is chloroform/ethyl acetate $(80: 20)$ at $1.80 \mathrm{~mL} / \mathrm{min}$; absorbance is monitored at 280 $\mathrm{nm}$. Each analysis is carried out by dissolving $25 \mathrm{mg}$ of sample in $5 \mathrm{~mL}$ of ethyl acetate. The flow rate of the sample is $1 \mathrm{~mL} / \mathrm{min}$ and ran for $30 \mathrm{~min}$.

\subsection{Spectral analysis of the active compound}

The UV-visible spectrum of the active compound showed two major peaks $\left(\lambda_{\max }\right)$ at 260 and $361 \mathrm{~nm}$ that are contributed by the 2-hydroxybenzoic acid substructure (Supplementary Figure 3a, http://www.ddtjournal.com/ docindex. php? year $=2015 \&$ kanno $=1$ ). This result is analogous with the results obtained from the UV-visible spectrum of the $\mathrm{scCO}_{2}$ extracted anacardic acid which showed two peaks at 246 and $314 \mathrm{~nm}$ (22).

The FT-IR spectrum of the extracted compound (Supplementary Figure 3b, http://www.ddtjournal.com/ docindex.php? year $=2015$ \&kanno $=1)$ showed peaks: 3,377.1 (Ar-OH), 2925.8 and 2854.5 (aliphatic C-H), 1463.9 (aromatic $\mathrm{CdC}), 1375.2$ (-COOH). (Aliphatic $\mathrm{CdC}$ ) nearly comparable result was reported for the FTIR spectrum of the $\mathrm{scCO}_{2}$ extracted anacardic acid (22).

The ${ }^{1} \mathrm{H}$ NMR results $\left[\mathrm{CDCl}_{3}, \delta(\mathrm{ppm})\right]$ clearly showed the substitution pattern of the aromatic ring (Supplementary Figure 4, http://www.ddtjournal.com/ docindex.php? year $=2015 \&$ kanno $=1)$. The presence of three aromatic protons observed at $\delta 6.791(\mathrm{~d}), 6.833$ (d), and $7.258(\mathrm{t})$ indicates that the extracted material contained only the trisubstituted benzene ring. The presence of the alkyl side chain (one of the substitutes) was indicated by alkenyl protons at $\delta 0.862(\mathrm{~m}, 3 \mathrm{H}$, 


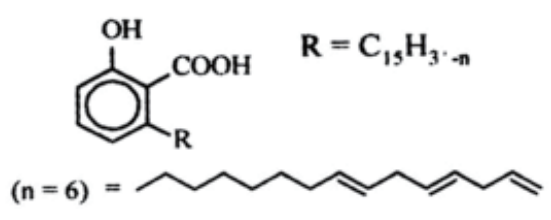

Figure 2. Chemical structure of A1.

$\left.-\mathrm{CH}_{3}\right), \delta 1.310,1.586,2.026,2.776$, and $2.983(\mathrm{~m}$, $\left.28 \mathrm{H},-\mathrm{CH}_{2-}\right), \delta 4.998$ (m, mixed, $\left.1 \mathrm{H},-\mathrm{CHdCH}-\right)$, and $\delta 5.354$ and 5.819 ( $\mathrm{m}, 4 \mathrm{H},-\mathrm{CHdCH}-)$. The phenolic and carboxyl (the other two substitutes) protons are assigned at $\delta 5.026(\mathrm{~m}$, mixed, $1 \mathrm{H})$ and 11.026 .

${ }^{13} \mathrm{C}$ NMR showed the similar pattern for $\left(\mathrm{CDCL}_{3}\right.$, $300 \mathrm{MHz}) 12.921 \mathrm{q}, 14.101 \mathrm{q}, 22.691 \mathrm{q}, 23.916$ q, 29.7 t, 35.121 t, 35.0 t, 36.135, 36.521, 37.107, 42.827, 43.181, 46.082, $70.023 \mathrm{t}, 73.561 \mathrm{~s}, 76.0413 \mathrm{~d}$, $81.321 \mathrm{~d}, 108.351 \mathrm{t}, 132.253 \mathrm{~d}, 136.731 \mathrm{~d}, 150.081 \mathrm{~s}$. The ${ }^{1} \mathrm{H}$ NMR spectrum and ${ }^{13} \mathrm{C}$ NMR spectrum of the compound is shown in (Supplementary Figure 5, http://www.ddtjournal.com/docindex. php? year $=2015$ \&kanno $=1$ ) Similar ${ }^{1} \mathrm{H}$ and ${ }^{13} \mathrm{C}$ NMR spectra are obtained for the $\mathrm{scCO}_{2}$ extracted anacardic acid (22).

All these analytical and spectral data appear to confirm the compound to be $\mathrm{C}_{15} \mathrm{H}_{3}{ }^{\prime} 6-[8(\mathrm{Z}), 11(\mathrm{Z})$, 14-pentadecatrienyl] salicylic acid (anacardic acid) (Figure 2). The molecular formula of the compound obtained from the elemental analysis and the molecular mass (343.248) by mass spectrometry is found to be $\mathrm{C}_{22} \mathrm{H}_{31} \mathrm{O}_{3}$.

\subsection{A1 inhibits VEGF-induced proliferation of Twist or Snail expressing $M C F-7$ cells}

The effect of A1 on the proliferation of Twist or Snail transfected or untransfected MCF-7 cells is investigated. Cells are treated for $24 \mathrm{~h}$ with or without VEGF (10 ng) or A1 $(50 \mu \mathrm{M})$ or VEGF plus A1 and cell proliferation rate is measured by ${ }^{3}[\mathrm{H}]$ thymidine incorporation assay. The resulting data demonstrated that VEGF increased proliferation of MCF-7 cells in which either Twist or Snail genes were overexpressed by transient transfection. Cell proliferation rate is increased by $84 \%$ and $72 \%$ in comparison with untransfected cells. Addition of A1 along with VEGF significantly decreased the proliferation rate of twist (62\%) and snail $(27 \%)$ compared to transfected control cells. These results suggest that A1 exhibits potent anti-proliferative activity (Figure 3).

\subsection{A1 inhibits VEGF-induced cell migration in Twist or Snail expressing cells}

The migration of cells to heal the wound made on a lawn of cells is measured at time zero and 24 hours. Effect of A1 is also studied on its ability to inhibit cell

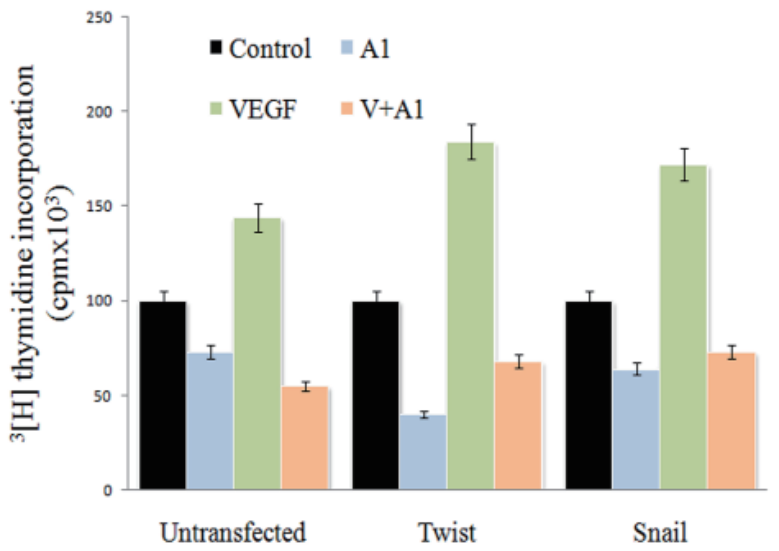

Figure 3. A1 inhibits VEGF-induced proliferation of MCF-7 cells. Effect of A 1 treatment on proliferation of Untransfected and Twist or Snail transfected cells was evaluated using thymidine incorporation assay. Cell proliferation data shown is mean \pm SEM of three samples. These results were similar in 3 independent experiments.

migration induced by Twist or Snail transfected cells in the mechanically wounded area. Results clearly showed that transfected cells when treated with VEGF filled the scratch area more rapidly than the cells which are treated with A1 or VEGF plus A1. Quantitative analysis of migration assay showed that VEGF treated cells ectopically expressing Twist or Snail effectively migrated faster in closing of wound when compared to that of cells treated with A1 alone or A1with VEGF. These results suggested that Twist or Snail increases the migration of MCF-7 cells and these transcription factors are downstream in VEGF signalling pathway in migrating MCF-7 cells (Figure 4)

\subsection{A1 inhibits VEGF-induced invasion in Twist or Snail overexpressing cells}

Epithelial to mesenchymal phenotype is an essential component which confers invasion of cancer cells. To obtain more conclusive evidence on the role of VEGF and its target transcription factors Twist and Snail in EMT, verification is done to understand if forced expression of Twist or Snail enhances VEGF triggered invasion of $\mathrm{MCF}-7$ cells when compared to the untransfected cells. A $46 \%$ and $38 \%$ increase is seen in VEGF induced invasion, in Twist or Snail over expressing cells respectively. As shown in Figure 5, the result indicated that in the presence of VEGF the invasion of Twist or Snail transfected cells into the gelatin coated transwell membrane is more efficient as compared to cells without the ectopic expression of Twist and Snail. Whereas in A1 treated cells, significant inhibition of invasiveness ( $63 \%$ and $52 \%$ ) was evident.

\subsection{Regulation of Twist, Snail and E-cadherin genes by VEGF and A1}

The results in Figure 6a indicate that in MCF-7 cells, 

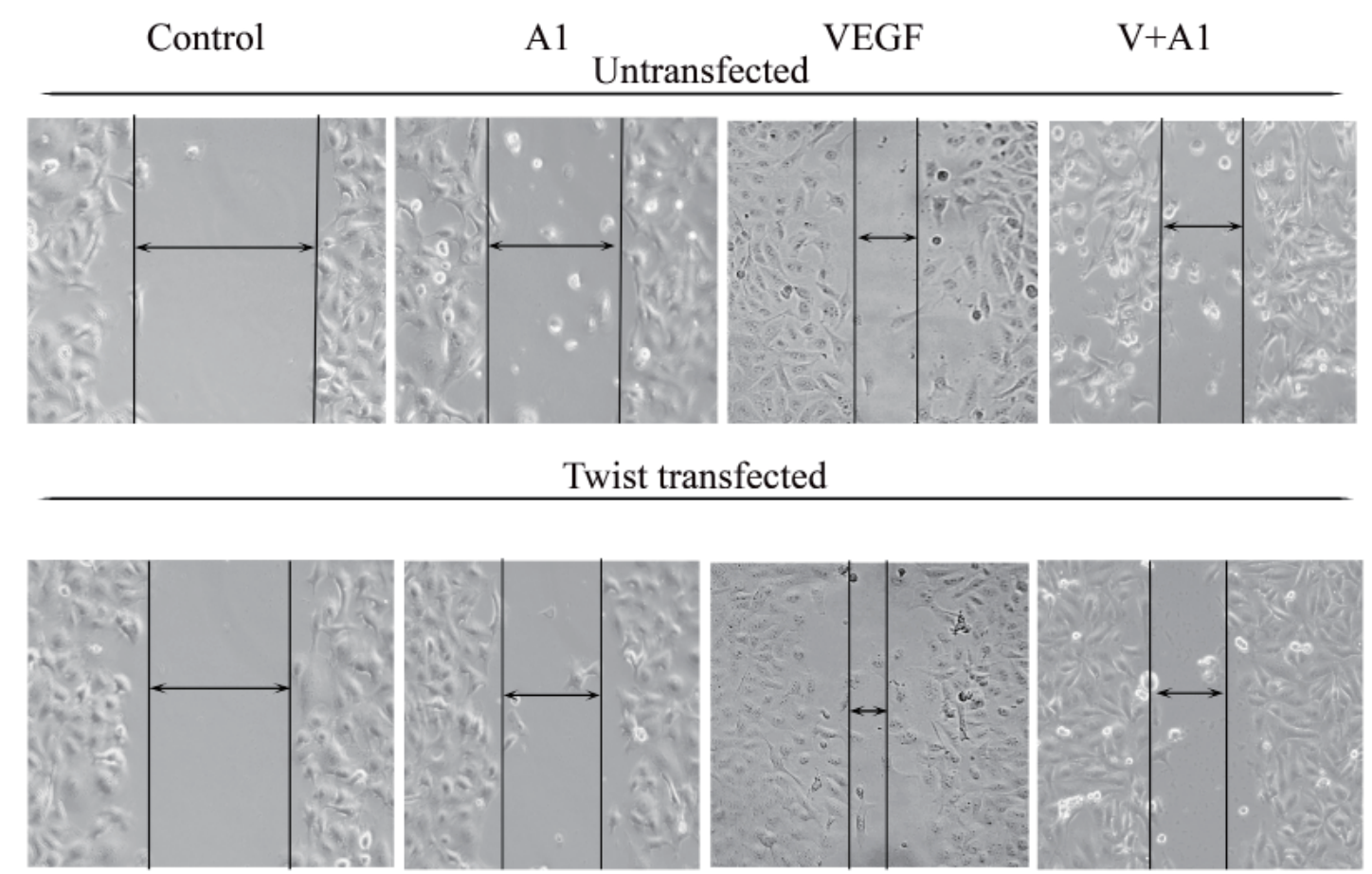

\section{Snail transfected}
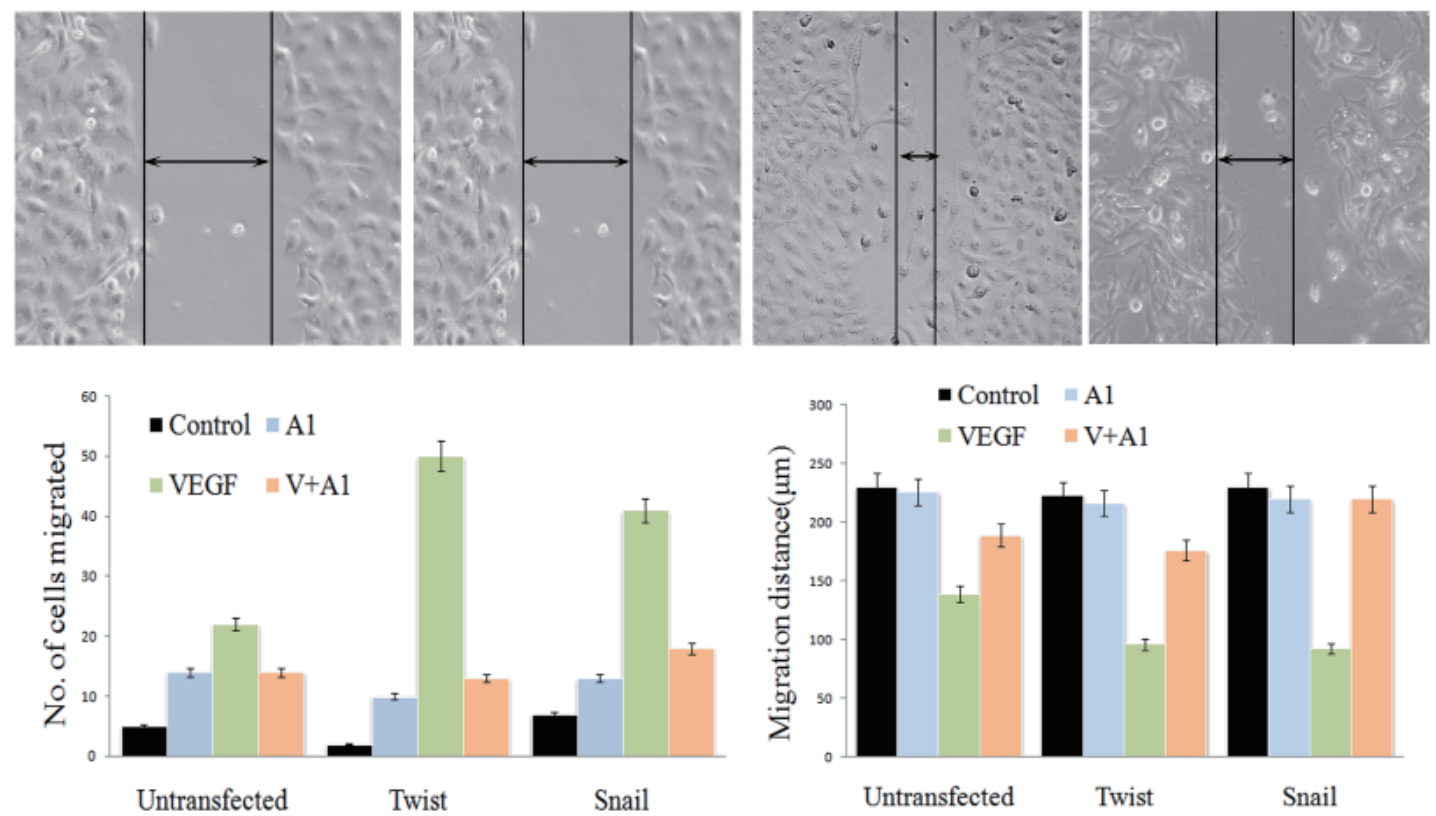

Figure 4. A1 inhibits VEGF-induced cell migration in Twist or Snail expressing cells. Effect of A1 treatment on migratory potential of Untransfected and Twist or Snail transfected cells was analyzed through wound healing assay. Representative photographs of initial and final wounds are shown at $40 \times$ magnification. The number of cells migrated and the distance of migration are shown as mean \pm SEM of three samples.

VEGF increases the expression of Twist and Snail genes. When compared to the expression of Snail gene, the expression of Twist gene is increased by two folds by VEGF. However, VEGF at the concentration used decreased E-cadherin expression. The data also indicated that A1 inhibits VEGF induced expression of both Twist and Snail genes and enhances the expression of E-cadherin gene in control untransfected MCF-7 cells but not in either Twist or Snail-transfected cells.
3.8. A1 increases expression of E-cadherin gene in cells overexpressing Twist or Snail genes

In order to verify if A1 up-regulates E-cadherin gene expression in MCF-7 cells in which Twist and Snail genes are overexpressed, E-cadherin promoter-luciferase reporter genes are co-expressed. The data on increased reporter gene activity (Figure 6b) indicates that $\mathrm{A} 1$ induces the expression of E-cadherin in MCF-7 cells in 


\section{Control A1 VEGF $\quad$ V+A1}
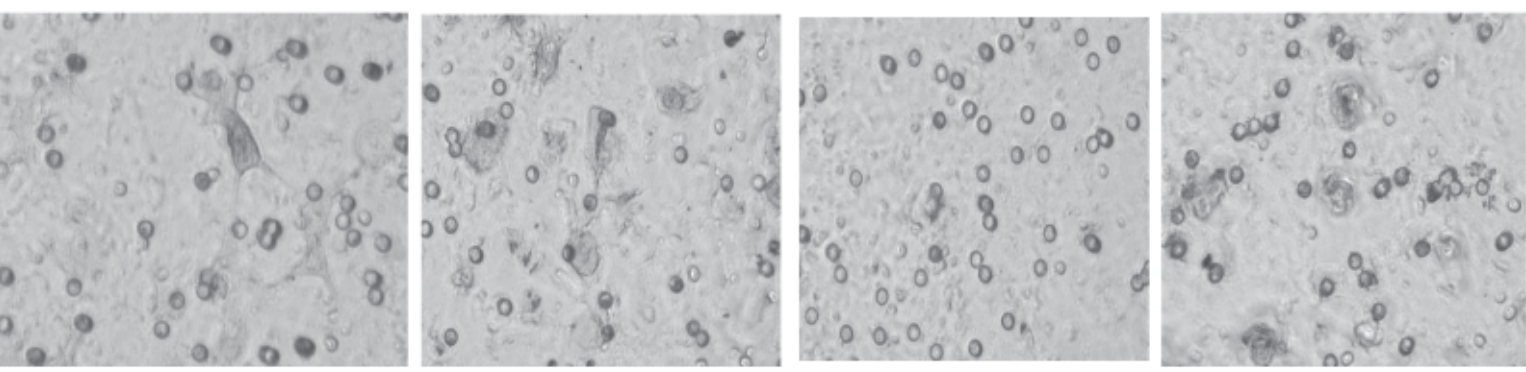

\section{Twist transfected}
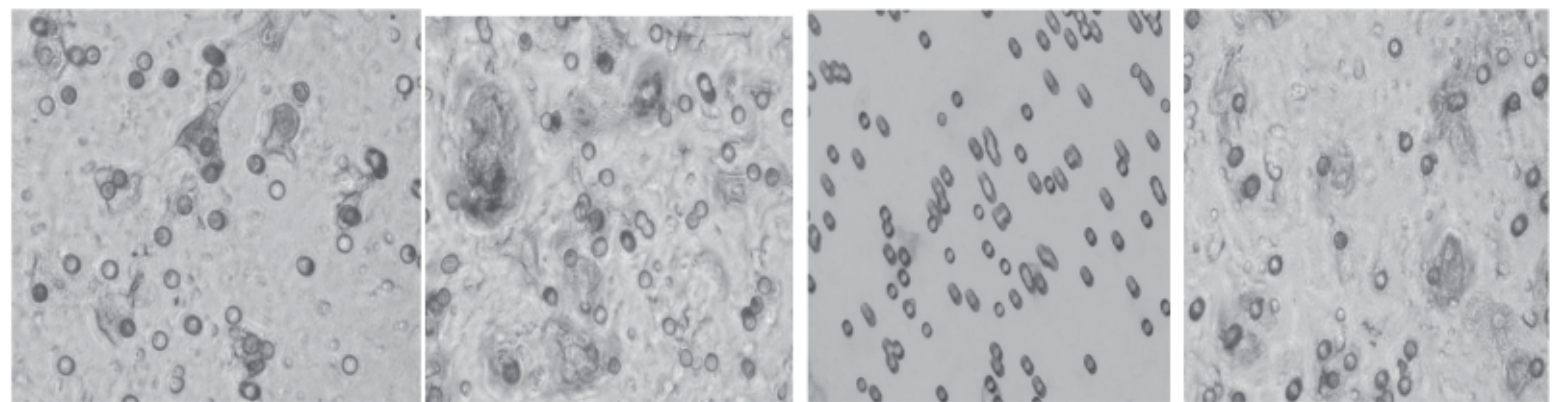

Snail transfected
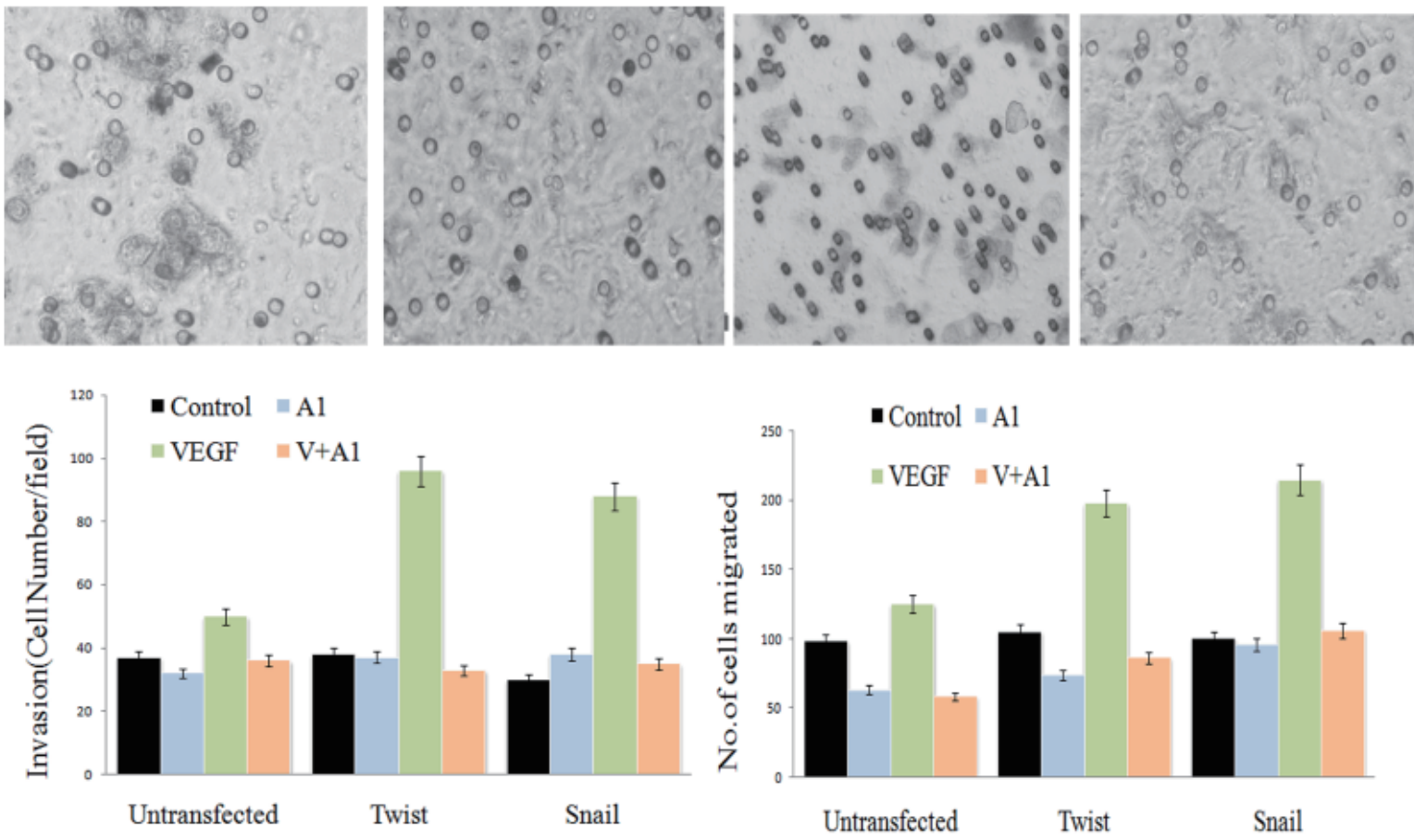

Figure 5. A1 inhibits VEGF induced invasion activity of MCF-7 cells. Effect of A1 treatment on the invasion potential of untransfected and Twist or Snail transfected cells was evaluated using transwell migration chambers. Cell invasion data shown is mean \pm SEM of three samples. These results were similar in 3 independent experiments.

context to overexpression of Twist or Snail genes. When compared to the activity of luciferase reporter (100 relative light units), in control Twist or Snail transfected cells, the activity is found in A1 treated cells either in presence or absence of VEGF which was 60 to $80 \%$ higher.

\subsection{A1 down regulates VEGF gene expression}

The effect of A1 on the transcriptional regulation of the VEGF promoter in HEK293 (normal) and U-87 (highly proliferating) cells is investigated further. Cells are transiently transfected with a VEGF promoter 


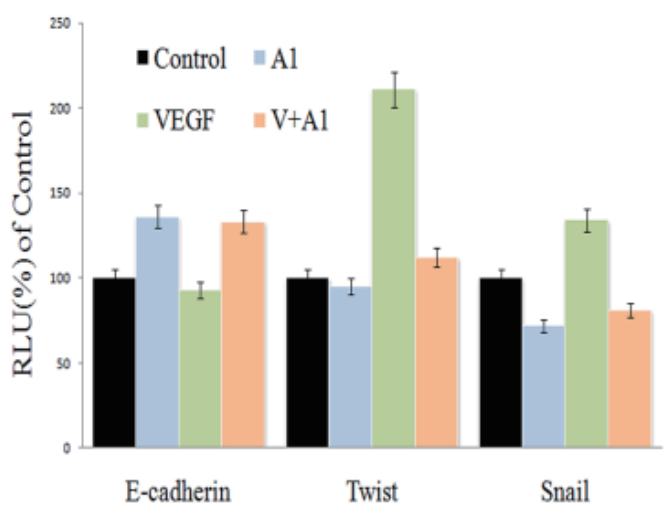

6(a)

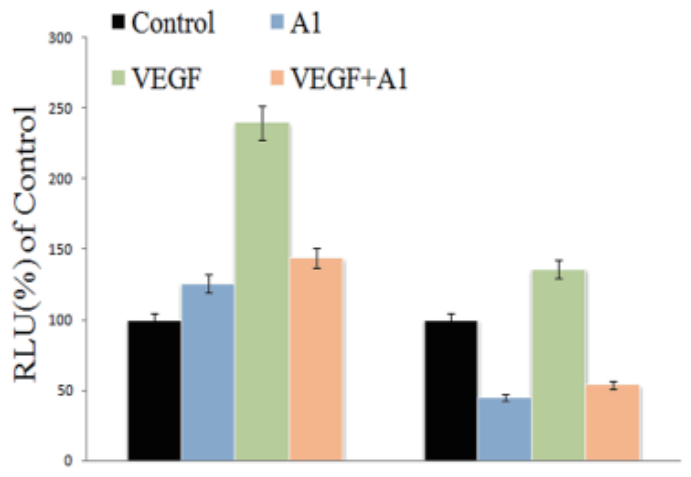

HEK293
U-87

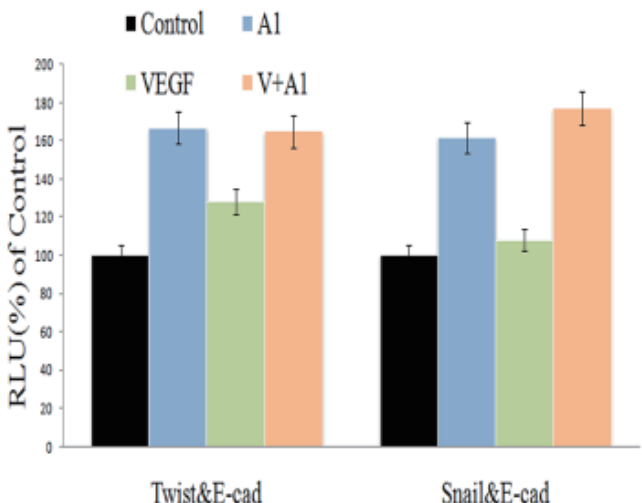

6(b)

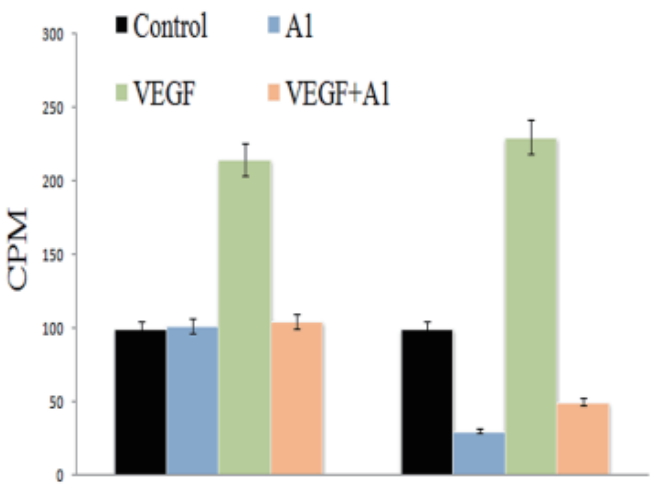

HEK293
U-87

6(c)

$6(d)$

Figure 6. A1 inhibits, VEGF upregulates Twist, Snail, and E-cadherin genes in MCF-7 cells. Promoter reporter analysis (a-c); CAT assay (d). (a) Regulation of Twist, Snail, and E-cadherin genes by VEGF and A1. MCF-7 cells were transiently transfected with E-cadherin or Twist or Snail promoter luciferase reporter genes. The cells were treated with A1 alone, with and without VEGF. After 48 hours of transfection cells were lysed and assayed for luciferase activity. 1-Control cells, 2-A1 alone, 3-VEGF, 4-VEGF + A1. Values are mean of triplicate \pm SEM. (b) A1 increases expression of E-cadherin gene in cells over expressing Twist or Snail genes. MCF-7 cells were transiently co transfected with E-cadherin/Twist or E-cadherin/Snail genes. The cells were treated with A1 alone, with and without VEGF. Forty-eight hours after transfection cells were lysed and assayed for luciferase activity. 1-Control cells, 2-A1 alone, 3-VEGF, 4-VEGF + A1. Values are mean of triplicate \pm SEM. (c) A1 down regulates VEGF gene expression. HEK293 and U-87 cells were transiently co-transfected with $2 \mu \mathrm{g}$ of reporter plasmid pLuc 2068 and $2 \mu \mathrm{g}$ of the $\beta$-galactosidase expression plasmid RSV- $\beta$ gal using calcium phosphate precipitation method. The cells were treated with A1 alone, with and without $10 \mathrm{ng}$ of VEGF. After 48 hours transfection, cells were assayed for luciferase activity. 1-Control cells, 2-A1 alone, 3-VEGF, 4-VEGF + A1. Values are mean of triplicates \pm SEM. (d) A1 promotes upregulation of Flt-1 gene. HEK293 and U-87 cells were transiently co-transfected with $2 \mu \mathrm{g}$ of plasmid Flt-1 CAT and $2 \mu \mathrm{g}$ of the $\beta$ galactosidase expression plasmid RSV $\beta$ gal. The cells were treated with A1 alone and with or without $10 \mathrm{ng}$ of VEGF. Forty-eight hours after transfection, cells were assayed for CAT enzyme activity. 1-Control cells, 2-A1 alone, 3-VEGF, 4-VEGF + A1. Values are mean of triplicates \pm SEM.

luciferase-reporter $(-2,018$ to +50$)$ plasmid pLUC $-2,068 \mathrm{bp}$. The results (Figure $6 \mathrm{c}$ ) indicated that VEGF upregulated its gene nearly 5 folds in the untransformed HEK293 cells. However, highly metastatic glioblastoma (U87) cell showed less intense upregulation of $V E G F$ gene by VEGF per se. The data also indicated that A1 inhibits VEGF gene expression both in HEK293 and U87 cell lines.

\subsection{A1 promotes upregulation of Flt-1 gene}

As VEGF regulates its own gene expression in both U-87 and HEK293 cell lines, a further investigation of the regulation of VEGF receptor Flt-1 gene expression by transiently transfecting with Flt-1 promoter-CAT reporter constructs is performed. The results in Figure $6 \mathrm{~d}$ indicate that when compared to the expression of VEGF receptor gene (Flt- 1$)$ in HEK 293 cells, the expression is significantly higher in U-87 cells. Upon verification of the effect of A1 on VEGF receptor Flt1 gene expression in these cell lines, the data revealed that A1 is a potent inhibitor of Flt-1 gene.

\subsection{A1 inhibits phosphorylation of JNK and ERK MAP kinases}

To delineate the molecular mechanism by which A1 inhibits VEGF induced metastasis, the potential involvement of MAP Kinases in transducing the molecular metastatic signals by VEGF and amelioration 


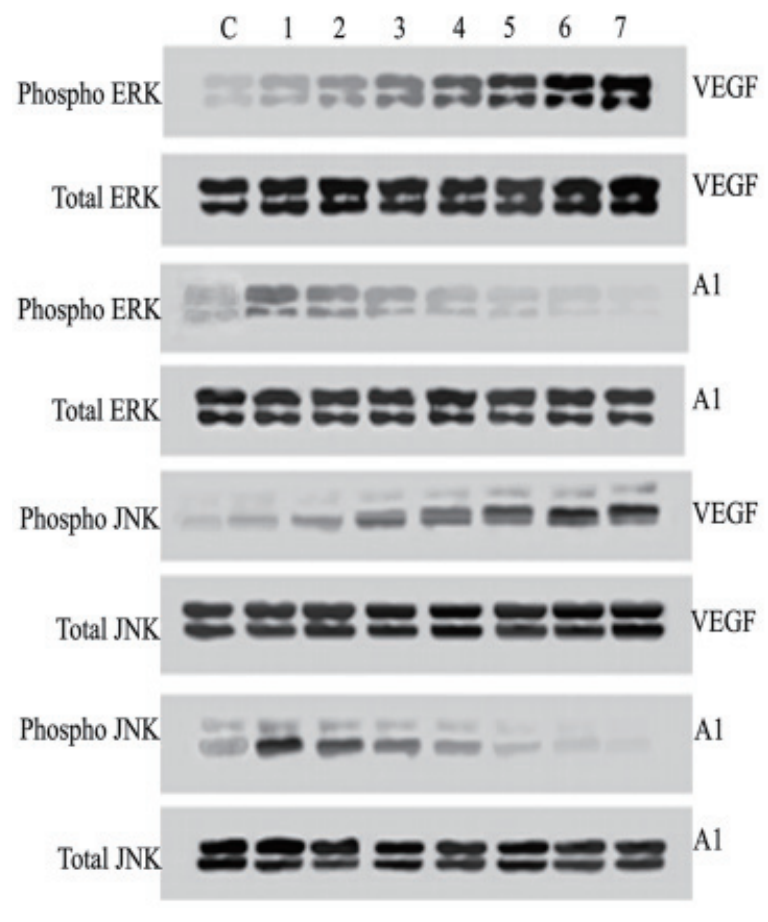

Figure 7. A1 inhibits VEGF-induced phosphorylation of ERK and JNK in glioma cells. Whole cell extracts were prepared from control and A1 treated U-87 cells. About $150 \mu \mathrm{g}$ of protein was resolved on SDS-PAGE (12.5\%). Western blot analysis was performed using antibodies against phospho JNK, total JNK, phospho ERK and total ERK. C: control cells with 0 min incubation with VEGF, 1: $2 \mathrm{~min}, 2: 5 \mathrm{~min}, 3: 10 \mathrm{~min}, 4$ : $15 \mathrm{~min}, 5: 30 \mathrm{~min}, 6: 60 \mathrm{~min}$, and 7: $120 \mathrm{~min}$ incubation with VEGF.

of the same by A1 is investigated by validating the enzyme activity using immunoblotting. The results in Figure 7 clearly indicate that VEGF activates both extra cellular signal regulated kinase (ERK) $1 / 2$ and phosphor-Jun NH2-terminal kinase (JNK) in a timedependent manner. Both the kinases are inhibited by A1. However the control cells showed an initial increase in kinase activity and whenever treated with A1 showed an inhibition. Interestingly, the total levels of both the kinases are not affected by A1. These results support a critical role of MAPK pathway in activating VEGF induced metastasis.

\subsection{A1 inhibits translocation of Sp1}

In highly metastatic U-87 cells, the transcription factor $\mathrm{Sp} 1$ is detected in the nucleus. Since they rapidly proliferate and multiply, $\mathrm{Sp} 1$ translocates from cytosol to nucleus. When treated with $\mathrm{A} 1$, the translocation of $\mathrm{Sp} 1$ is inhibited and is found in the cytosolic region of the cells and this is confirmed by electrophoretic mobility shift assay (EMSA) using nuclear extracts prepared from control as well as A1 treated U-87 cells and oligonucleotides for $\mathrm{Sp} 1$. The results indicated that there is strong inhibition of binding of Sp1 transcription factor to its cognate promoter sequence on $V E G F$ gene in A1 treated U-87 cells. In contrast, in the nuclear

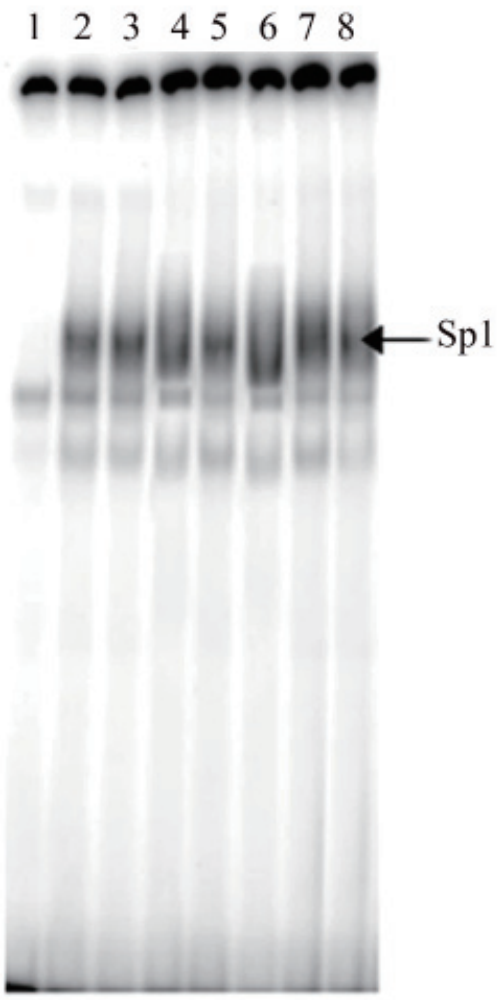

Figure 8. A1 inhibits binding of Sp1 to VEGF promoter site. Nuclear extracts were prepared from U-87 cells treated with or without A1. Sp1 DNA binding activity was assayed by EMSA using Sp1 oligonucleotides (Lane 1: Labelled probe, Lane 2: Labelled probe + control nuclear extract; Lanes 3-7: nuclear extract of $4 \mathrm{~h}, 8 \mathrm{~h}, 16 \mathrm{~h}, 32 \mathrm{~h}$, and $48 \mathrm{~h}$ time kinetics with $10 \mu \mathrm{g}$ of A1 + labelled oligos; Lane 8: Supershift of Sp1).

extract of control U-87 cells, there is strong binding of $\mathrm{Sp} 1$ to its promoter sequence (Figure 8).

\section{Discussion}

The data presented in the present study clearly establishes the role of E-cadherin in tumor invasion and metastasis. In this study two cell lines, MCF-7, which is tumorigenic but weakly metastatic and U-87 glioma cells which are highly metastatic are used. It is shown that exogenous expression of either Twist or Snail in MCF-7 cells, confer on them better ability to migrate and invade in vitro. Furthermore, the mechanisms that might be responsible for this effect have been elucidated.

Epithelial to mesenchymal transition is a crucial process in embryogenesis (23) and tumor progression, by which epithelial cells show loss of cell-cell adhesion, reduced basal cell polarity and acquired fibroblastic phenotype with increased cell motility, migration and metastasis (24). The process is triggered by autocrine and paracrine signals. Natural compounds with an anticancer potential have to be endowed with benefits such as, being non-toxic, cost-effective, physiologically bioavailable and have multiple molecular targets their use in treating human cancers. Identification of mechanism- 
based naturally occurring inhibitors of tumour invasion and metastasis holds promise for treatment of metastatic tumors. Studies have identified diet derived natural products such as garlic-derived chemicals (25), soy constituent genistein $(26,27)$, green tea polyphenols (28) and vegetable constituent benzyl isothiocyanate as natural product derived inhibitors of EMT in cancer cells (29). It has been reported that herbal medicines including $A$. occidentale $\mathrm{L}$. indicates a lack of clinical efficacy for supporting their use in patients (30). Although there are lot of importance of $A$. occidentale and its major constituents in human health, little is known about its anti-angiogenic and anti-metastatic ability and the mechanism for its pharmacological activities. We have reported that $A$. occidentale crude extract inhibits in vivo angiogenesis by repression of the cytokine VEGF gene expression (4).

Activity-guided (formation of tube like structures by HUVEC's) fractionation of the leaves of $A$. occidentale L. using different solvents resulted in ethyl acetate extract exhibiting maximum anti-angiogenic efficacy by inhibiting tube formation by HUVEC's. Isolation, purification, and characterization of the active substance from ethyl acetate extract yielded us the active compound which was further characterised using LC-MS, UV-visible spectrum, FT-IR spectrum, ${ }^{1} \mathrm{H}$ NMR spectrum and ${ }^{13} \mathrm{C}$ NMR spectrum. Anacardic acid isolated from natural CNSL using supercritical carbon dioxide $\left(\mathrm{scCO}_{2}\right)$ has revealed a similar HPLC profile, LC-MS analysis results, UV-visible spectrum, FT-IR spectrum, ${ }^{1} \mathrm{H}$ NMR spectrum and ${ }^{13} \mathrm{C}$ NMR spectrum (21). Analogous spectral results have been reported during the isolation and identification of anacardic acid derivatives from Brazilian propolis. Anacardic acid obtained by CNSL has shown comparable spectroscopic results. The combination of these spectroscopic and chromatography results, with reference to the findings reported in the literature, confirmed that the plant extract (EA1.1) obtained and structurally characterized was Anacardic acid (A1).

The data presented in the present study clearly establishes the role of E-cadherin in tumor invasion and metastasis. It is shown that exogenous expression of either Twist or Snail in MCF-7 cells, confer on them better ability to migrate and invade in vitro. Furthermore, examination of the mechanisms that might be responsible for this effect revealed that evidence from previous reports indicate that pancreatic cancers with the deregulated VEGFR-1 pathway possess a high likelihood for local invasion, molecular alterations and subsequent metastasis (31). Previous evidences suggest that ectopic expression of Twist resulted in breast cancer cells metastasis to lung in animal model (17). This model also fits with the reported involvement of Snail in local invasion and lymph node metastases of breast tumor $(18,32)$. In this study, it is shown that Twist or Snail transfected MCF-7 cells undergo representative EMT, characterized by the acquisition of mesenchymal phenotype upon treating the transfected cells with VEGF. Current results clearly indicate that VEGF treatment of Twist or Snail transfected cells increased proliferation, migration and invasion when compared with untransfected cells. A1 significantly inhibited cell proliferation, migration and invasion. These results are consistent with the mechanistic role of Twist and Snail signaling in the processes of EMT and that the suppression of Twist and Snail signaling leads to the reversal of EMT. Collectively, the current result suggests that the suppression of VEGF induced Twist or Snail gene by A1 treatment strategies could be useful for the reversal of EMT phenotype.

Over-expression of Twist and Snail in breast cancer cells induces EMT via upregulation of $V E G F$ gene expression thus facilitating metastasis in high grade tumor, but not in non-metastatic tumor (33, 34). Accordingly, the results presented have shown that VEGF significantly increases Twist and Snail gene expression and down-regulates E-cadherin gene expression when compared to the expression of the afore said genes in cells treated with A1. Because of A1 suppresses expression of Twist and Snail gene and increases transcription of E-cadherin, it is reasonable to conclude that transcriptional repression of VEGF induced Twist and Snail genes represent the mechanism by which A1 inhibits EMT.

The present study determines that A1 has a role in the prevention and /or treatment of metastatic tumors where epithelial to mesenchymal transition is an underlying mechanism. To the best of our knowledge this is the first study that reveals the molecular mechanism of anti EMT activity of A1. It is further shown that inhibition of VEGF secretion could be due to inhibition of $\mathrm{Sp} 1$ translocation to nucleus. Sp1 transcription factor regulates many genes involved in tumor promotion, angiogenesis and metastasis (35). Thus, it is becoming increasingly clear that compounds that block Sp1 activation could be highly useful for the treatment of cancer. This is confirmed by electrophoretic mobility shift assay (EMSA) where A1 inhibited the binding of $\mathrm{Sp} 1$ transcription factor to its promoter sequence on the VEGF gene in U-87 cells. In the current molecular study, A1 diminished ERK 1/2, and JNK phosphorylation in U-87 cells.

Current study systematically demonstrated and revealed the molecular mechanism of action of $\mathrm{A} 1$ as a novel tumor metastatic inhibitor and an EMT inhibitor. This confirms its pharmacological value with multiple targets and contributes to drug development.

\section{Acknowledgements}

The authors thank Department of Biotechnology (DBT) New Delhi, India (No.BT/IN/DBT-CREST awards/25/ BPS/2012-2013), University Grant Commission- 
Special Assistance Programme-Department of Special Assistance (UGC-SPA-DSA) Government of India (No. $\mathrm{f}$ 4-1/2013(SAP-II) 14 October 2014) and the Indian Council of Medical Research (ICMR; No.3/2/2/101/2011-NCDIII), New Delhi for financial support.

\section{References}

1. Doss VA, Thangavel KP. Antioxidant and antimicrobial activity using different extracts of Anacardium occidentale L. International Journal of Applied Biology and Pharmaceutical Technology. 2011; 2:436-443.

2. Mathivadhani P, Shanthi P, Sachdanandam P. Hypoxia and its downstream targets in DMBA induced mammary carcinoma: Protective role of Semecarpus anacardium nut extract. Chem Biol Interact. 2007; 167:31-40.

3. Chakraborty S, Roy M, Taraphdar AK, Bhattacharya RK. Cytotoxic effect of root extract of Tiliacora racemosa and oil of Semecarpus anacardium nut in human tumor cells. Phytother Res. 2004; 18:595-600.

4. Sheela M, Kaveri K, Salimath BP. Inhibition of in vivo angiogenesis by Anacardium occidentale L. involves repression of the cytokine $V E G F$ gene expression. Drug Discov Ther. 2008; 2:234-244.

5. Frixen UH, Behrens J, Sachs M, Eberle G, Voss B, Warda A, Löchner D, Birchmeier W. E-cadherin-mediated cellcell adhesion prevents invasiveness of human carcinoma cells. J Cell Biol. 1991; 113:173-185.

6. Vleminckx K, Vakaet L Jr, Mareel M, Fiers W, Van Roy F. Genetic manipulation of E-cadherin expression by epithelial tumor cells reveals an invasion suppressor role. Cell. 1991; 66:107-119.

7. Frixen UH, Nagamine Y. Stimulation of urokinasetype plasminogen activator expression by blockage of E-cadherin-dependent cell-cell adhesion. Cancer Res. 1993; 53:3618-3623.

8. Perl AK, Wilgenbus P, Dahl U, Semb H, Christofori G. A causal role for E-cadherin in the transition from adenoma to carcinoma. Nature. $1998 ; 392: 190-193$.

9. Christofori G, Semb H. The role of the cell-adhesion molecule E-cadherin as a tumour-suppressor gene. Trends Biochem Sci. 1999; 24:73-76.

10. Hay ED. An overview of epithelio-mesenchymal transformation. Acta Anat (Basel). 1995; 154:8-20.

11. Kang Y, Massague J. Epithelial-mesenchymal transitions: Twist in development and metastasis. Cell. 2004; 118:277-279.

12. Elliott BE, Hung WL, Boag AH, Tuck, Alan B. The role of hepatocyte growth factor (scatter factor) in epithelial mesenchymal transition and breast cancer. Can J Physiol Pharmacol. 2002; 80:91-102.

13. Mercurio AM, Lipscomb EA, Bachelder RE. Nonangiogenic function of VEGF in breast cancer. J Mammary Gland Boil Neoplasia. 2005; 10:283-290.

14. Thiery J, Sleeman JP. Complex networks orchestrate epithelial-mesenchymal transitions. Nat Rev Mol Cell Biol. 2006; 7:131-142.

15. Hiroharshi S. Inactivation of the E-cadherin-mediated cell adhesion system in human cancers. Am J Pathol. 1998; 153:333-339.

16. Yang J, Mani SA, Donaher JL, Ramaswamy S, Itzykson RA, Come C, Savagner P, Gitelman I, Richardson A, Weinberg RA. Twist, a master regulator of morphogenesis, plays an essential role in tumor metastasis. Cell. 2004; 117:927-939.

17. Ashton AW, Yokata RR, John G. Inhibition of endothelial cell migration intercellular communication and vascular tube formation by thromboxane A. J Biol Chem. 1999; 274:35562-35570.

18. Zeng H, Sanyal S, Mukhopadhyay D. Tyrosine residues 951 and 1059 of vascular endothelial growth factor receptor-2 (KDR) are essential for vascular permeability factor/vascular endothelial growth factor-induced endothelium migration and proliferation, respectively. J Biol Chem. 2001; 276:32714-32719.

19. Pang X, Yi T, Yi Z, Cho SG, Qu W, Pinkaew D, Fujise K, Liu M. Morelloflavone, a biflavonoid, inhibits tumor angiogenesis by targeting rho GTPases and extracellular signal-regulated kinase signaling pathways. Cancer Res. 2009; 69:518-525.

20. Liang CC, Park AY, Guan JL. In vitro scratch assay: A convenient and inexpensive method for analysis of cell migration in vitro, Nat Protoc. 2007; 2:329-333.

21. Jayaraman L, Moorthy NC, Murthy KG, Manley JL, Bustin M, Prives C. High mobility group protein-1 (HMG1) is a unique activator of p53. Genes Dev. 1998; 12:462472.

22. Philip JY, Da Cruz Francisco J, Dey ES, Buchweishaija J, MKayula LL, Ye L. Isolation of anacardic acid from natural nut shell liquid (CNSL) using supercritical carbon dioxide. J Agric Food Chem. 2008; 56:9350-9354.

23. Barrallo-Gimeno A, Nieto M. The Snail genes as inducers of cell movement and survival: Implications in development and cancer. Development. 2005; 132:31513161.

24. Thiery J. Epithelial-mesenchymal transitions in development and pathologies. Curr Opin Cell Biol. 2003; 15:740-746.

25. Chu Q, Ling MT, Feng H, Cheung HW, Tsao SW, Wang X, Wong YC. A novel anticancer effect of garlic derivatives: Inhibition of cancer cell invasion through restoration of E-cadherin expression. Carcinogenesis. 2006; 11:21802189.

26. Zhang LL, Li L, Wu DP, Fan JH, Li X, Wu KJ, Wang $\mathrm{XY}, \mathrm{He}$ DL. A novel anti-cancer effect of genistein: Reversal of epithelial mesenchymal transition in prostate cancer cells. Acta Pharmacol Sin. 2008; 29:1060-1068.

27. Su Y, Simmen RC. Soy isoflavone genistein upregulates epithelial adhesion molecule E-cadherin expression and attenuates beta-catenin signaling in mammary epithelial cells. Carcinogenesis. 2009; 30:331-339.

28. Belguise K, Guo S, Yang S, Rogers AE, Seldin DC, Sherr $\mathrm{DH}$, Sonenshein GE. Green tea polyphenols reverse cooperation between c-Rel and CK2 that induces the aryl hydrocarbon receptor, slug, and an invasive phenotype. Cancer Res. 2007; 67:11742-11750.

29. Sehrawat A, Singh SV. Benzyl isothiocyanate inhibits epithelial-mesenchymal transition in cultured and xenografted human breast cancer cells. Cancer Prev Res. 2011; 4:1107-1117.

30. Yu XQ, Ao J, Ling E. A Toll receptor from Manduca sexta is in response to Escherichia coli infection. Mol Immunol. 2008; 45:543-552.

31. Yang AD, Camp ER, Fan F, Shen L, Gray MJ, Liu W, Somcio R, Bauer TW, Wu Y, Hicklin DJ, Ellis LM. Vascular endothelial growth factor receptor-1 activation mediates epithelial to mesenchymal transition in human pancreatic carcinoma cells. Cancer Res. 2006; 66:46-51. 
32. Côme C, Magnino F, Bibeau F, De Santa Barbara P, Becker KF, Theillet C, Savagner P. Snail and Slug play distinct roles during breast carcinoma progression. Clin Cancer Res. 2006; 12:5395-5402.

33. Hajra KM, Chen DY, Fearon ER. The SLUG zinc-finger protein represses E-cadherin in breast cancer. Cancer Res. 2002; 62:1613-1618.

34. Cheng CW, Wu PE, Yu JC, Huang CS, Yue CT, Wu CW, Shen CY. Mechanisms of inactivation of E-cadherin in breast carcinoma: Modification of the two-hit hypothesis of tumor suppressor gene. Oncogene. 2001; 20:38143823.

35. Rayet B, Gelinas C. Aberrant rel/nfkb genes and activity in human cancer. Oncogene. 1999; 18:6938-6947.

(Received November 5, 2014; Revised December 21, 2014; Re-revised February 27, 2015; Accepted February 27, 2015) 